\title{
Coordinating Committee
}

National Cancer Institute

\section{Source}

National Cancer Institute. Coordinating Committee. NCI Thesaurus. Code C142465.

A committee that a sponsor may organize to coordinate the conduct of a multicenter trial. $(\mathrm{ICH})$ 